\title{
Knowledge and Practice Regarding Breastfeeding Among Mothers Attending Immunization Clinic in Nepalgunj Medical College Teaching Hospital
}

\author{
Janaki $\mathrm{P}^{1}$, Mishra $\mathrm{P}^{2}, \mathrm{~N}$ Thapa ${ }^{3}$
}

\begin{abstract}
Background: Breastfeeding has been accepted as the most vital intervention for reducing infant mortality and ensuring optimal growth and development of children. The current study aimed to assess the knowledge and practice regarding breastfeeding among mothers attending immunization clinic. Methods: A cross sectional study was mothers having children under 1 year of age, who attended their children for vaccination and for the treatment of other minor illnesses. The purposive sampling technique was used for selecting the study subjects. Information regarding patients' demographics, knowledge and practice towards breastfeeding were collected from these mothers on a pre-designed and pretested questionnaire. Results: A total of 208 women with children between 6 months and 12 months were included in the study. Their age ranged between 18 and 37 years with the mean of $24.9 \pm 4.1$. Overall mother's breastfeeding knowledge was good among 35\% and excellent among $22 \%$ of them while it was unsatisfactory among $43 \%$ of the mothers. Breastfeeding in the first 6 months was practiced by $42 \%$ of the participated mothers. Only $23 \%$ practiced exclusive breast feeding. Among those who breastfed their babies, 51\% initiated breastfeeding in the first hour of birth, $21 \%$ between $2-4$ hours and only $20 \%$ initiated it after 24 hours. Only $73 \%$ of mother had not given any prelacteal feeding to their babies. No enough breast milk (47.9\%), crying hungry (31.5\%), work-related problems (13.7\%) \& mothers' illness $(6.8 \%)$ were the commonly reported barriers against exclusive breastfeeding. Conclusion: The prevalence of EBF for up to 6 months of age was still low as per WHO recommendations. The mother's perception of "insufficient breast milk" was also the main reason for introducing other foods. Optimal breastfeeding promotion campaigns need to be carried out within the existing health care system such as the antenatal, after delivery and vaccination clinics.
\end{abstract}

Key words: Breastfeeding, exclusive, prevalence, knowledge, practice

\section{INTRODUCTION}

Good infant feeding and healthcare are critical for growth and development of children in the first few years of life ${ }^{1}$. Optimal infant feeding practice recommended by World Health Organization (WHO) and United Nations Children's Fund involves early initiation of breastfeeding within 1 hour of birth; exclusive breastfeeding for the first 6 months of life; and the introduction of nutritionally-adequate and safe complementary (solid) foods at 6 months together with continued breastfeeding up to 2 years of age or beyond ${ }^{2}$.

Breastfeeding has been accepted as the most vital intervention for reducing infant mortality and ensuring optimal growth and development of children ${ }^{3}$. About 800000 children's lives could be saved every year among children under 5 , if all children 0-23 months were optimally breastfed ${ }^{4}$. Breastfeeding is the ideal method suited for the physiological and psychological needs of

\footnotetext{
1. Mrs. Janaki Parajuli

2. Dr. Pradip Mishra

3. Dr. Narbadha Thapa
}

\section{Address for correspondence: \\ Mrs. Janaki Parajuli \\ Department of Community Medicine \\ Nepalgunj Medical College Teaching Hospital, Kohalpur, Banke, Nepal \\ Email: meetjanaki@hotmail.com}

an infant ${ }^{5}$. Poor breastfeeding practices are widespread. It is estimated that sub-optimal breastfeeding, especially nonexclusive breastfeeding in the first 6 months of life, results in 1.4 million deaths and $10 \%$ of the disease burden in children younger than 5 years of age ${ }^{6}$. Reviews of studies from developing countries show that infants who are not breastfed are 6 to 10 times more likely to die in the first months of life than infants who are breastfed ${ }^{7,8}$.

The key to successful breastfeeding is Information, Education and Communication strategies aimed at behavior change. For such a promotional campaign to be effective, attitudes and practices of health providers must be improved ${ }^{9}$. Exclusive breastfeeding stands out as the single most effective intervention for child survival ${ }^{10}$. Universalizing early (within one hour) and exclusive breastfeeding for 6 months, is viewed as a major public health intervention to reduce the child mortality, particularly, in the neonates and infants ${ }^{11,12}$.

A study done in Australia found that the level of basic breastfeeding knowledge of Australian midwives was adequate but there are deficits in key areas. They noted that knowledge variations by midwives may contribute to conflicting advice experienced by breast-feeding women ${ }^{13}$.

Factors that are positively associated with breastfeeding at six months included a very strong desire to breastfeed, having 
been breastfed oneself as a baby, and being older. On the other hand, factors that are negatively associated included a woman having no intention to breastfeed for six months or more, baby receiving formula while in hospital, smoking 20 or more cigarettes per day before pregnancy, not attending childbirth education sessions, and having self-reported anxiety or depression which was a problem in the six months after birth ${ }^{14}$. Interventions that seek to increase breastfeeding should consider focusing on women who are most at risk of early discontinuation of breastfeeding. Lack of knowledge, nonsupportive behaviours and attitudes of maternity nurses, inconsistent advice, and minimal prenatal encouragement to breastfeed have been cited as barriers to breastfeeding ${ }^{15}$. Some nurses and physicians are less than supportive of breastfeeding and tend to encourage mothers to supplement with formula or to give up altogether if they experience difficulties with breastfeeding ${ }^{16}$.

Another study noted that, across disciplines, inadequate professional support for breastfeeding has been identified in the literature. They also stated that: "The adequacy of health professionals' performance in the promotion of breastfeeding has been questioned repeatedly ${ }^{\prime \prime 17}$. Physicians have significant educational needs in the area of breastfeeding management ${ }^{18}$. Breastfeeding offers numerous health advantages to children, mothers, families, and society. The American Academy of Pediatrics calls for enthusiastic support and involvement of paediatricians in the promotion and practice of breastfeeding.

The mean total duration of breastfeeding in Nepal, like most other low and middle income countries, is long and usually more than two years ${ }^{19}$, but data on EBF up to six months of age as well as continuous breast feeding practices are scarce. Information on breastfeeding practices and the factors influencing them is important for successful campaigns. Hence, we undertook cross-sectional survey in an immunization clinic of tertiary hospital, Kohalpur, Nepal. The current study aimed to assess the knowledge and practice regarding breastfeeding among mothers attending immunization clinic.

\section{MATERIAL AND METHODS}

A cross sectional study was carried out in immunization clinic which runs once a week on Nepalgunj Medical College Teaching Hospital, Kohalpur, Banke, Nepal between August 2014 to December 2014.The study subjects were mothers having children aged under 1 year of age, who attended their children for vaccination and for the treatment of other minor illnesses. The purposive sampling technique was used for collecting to select the study subjects. Information regarding patients' demographics, knowledge and practice towards breastfeeding were collected from these mothers on a predesigned and pretested questionnaire ${ }^{20}$.

It comprised 3 parts: Sociodemographic characteristics, knowledge about breast feeding and breast feeding practices.
Knowledge on breastfeeding included 38 items, covering the following scopes of knowledge on breastfeeding: general knowledge, colostrum, advantages to mothers and babies, effective feeding method, duration of feeding, complementary feeding, problems with breastfeeding. Each item had categorical responses of yes, no, or do not know. A correct response will be scored as ' 1 ', whereas a wrong or do not know response will be scored as ' 0 '. Total knowledge score ranged from 0 to 38, with higher scores indicating more knowledge. Knowledge of mothers whose scores are less than $50 \%$ (i.e., $<19$ ) were considered as "unsatisfactory", $50 \%$ to $<75 \%$ (i.e., 19-28) as "good", while mothers' knowledge scores $75 \%$ or more (i.e., 29-38) were considered as "excellent". Breast feeding practices were assessed with initiation of breastfeeding, colostrum feeding, prelacteal feeding and exclusive breastfeeding upto six months of age or not. Before collecting the information, permission was taken from the institute authority and verbal consent was taken from the respondents. The data was entered in SPSS 17 software package and analyzed.

\section{RESULTS}

\section{Baseline characteristics of respondents}

A total of 208 women, with children aged between 6 months and 12 months, attending immunization clinic were included in the study. Their sociodemographic characteristics were presented in Table I. Age of the women ranged between 18 and 37 with the mean of $24.9 \pm 4.1$. Early marriage was done by $68.3 \%$ of them with $38 \%$ teenage pregnancy. $40.9 \%$ of the respondents came from rural area. Only $70 \%$ of the respondents live in their own house. Although $54 \%$ of the respondents completed their higher secondary level of education, $3 / 4^{\text {th }}$ of them were housewife.

Table II depicts the children information. Almost $3 / 4^{\text {th }}$ of the children were male, $53.4 \%$ less than 9 months with $96 \%$ hospital delivery.

\section{Breastfeeding Knowledge}

Advice regarding breastfeeding was received by almost $73 \%$ of the women participated in the study. Table 3 shows that majority of the women (67.3\%) were aware of the benefits of breastfeeding for reducing the frequency of diarrhoea. However they had unsatisfactory knowledge regarding other benefits to babies. Regarding benefits to mothers majority $87 \%$ were aware that mother who practiced breastfeeding had a low risk of getting breast cancer, prevent breast engorgement (72\%), helps achieving pre-pregnancy weight faster. Only $23 \%$ were knowing that exclusive breastfeeding is beneficial in spacing birth. It is evident that the knowledge of participated mother regarding colostrums in insufficient except its definition where $72 \%$ of them properly answered that it is the mother's early milk which was thick, sticky and yellowish in colour. 
Parajuli et al.: Knowledge and Practice Regarding Breastfeeding Among Mothers Attending Immunization Clinic in Nepalgunj Medical College Teaching Hospital

\begin{tabular}{|c|c|c|c|}
\hline Socio demographic Data & & Frequency & Percentage \\
\hline \multirow[t]{3}{*}{ Age(years) } & $<20$ & 12 & 5.8 \\
\hline & $20-30$ & 181 & 87 \\
\hline & $>30$ & 15 & 7.2 \\
\hline Mean \pm SD & $24.9 \pm 4.1$ & & \\
\hline \multirow[t]{2}{*}{ Age at marriage (years) } & $<20$ & 142 & 68.3 \\
\hline & $>=20$ & 66 & 31.7 \\
\hline \multirow[t]{2}{*}{ Age at first child } & $<20$ & 79 & 38 \\
\hline & $>=20$ & 129 & 62 \\
\hline \multirow[t]{2}{*}{ Address } & Rural & 85 & 40.9 \\
\hline & Urban & 111 & 53.4 \\
\hline \multirow[t]{2}{*}{ Residence } & Own house & 145 & 69.7 \\
\hline & Rent & 63 & 30.3 \\
\hline \multirow[t]{2}{*}{ Living in joint family } & Yes & 94 & 45.2 \\
\hline & No & 114 & 54.8 \\
\hline \multirow[t]{4}{*}{ Education } & Illiterate & 21 & 10.1 \\
\hline & Primary & 17 & 8.2 \\
\hline & Secondary & 56 & 26.9 \\
\hline & Higher sec and above & 114 & 54.8 \\
\hline \multirow[t]{4}{*}{ Husband's education } & Illiterate & 2 & 1 \\
\hline & Primary & 27 & 13 \\
\hline & Secondary & 54 & 26 \\
\hline & Higher sec and above & 125 & 60.1 \\
\hline \multirow[t]{3}{*}{ Occupation } & Housewife & 158 & 76 \\
\hline & Governmental & 15 & 7.2 \\
\hline & Private & 35 & 16.8 \\
\hline \multirow[t]{3}{*}{ Husband's occupation } & Governmental & 39 & 18.8 \\
\hline & Private & 163 & 73.6 \\
\hline & No work & 16 & 7.7 \\
\hline
\end{tabular}

Table I: Sociodemographic characteristics of respondents $(n=208)$

\begin{tabular}{|l|c|c|c|}
\hline Characteristics of data & & Frequency & Percentage \\
\hline Sex & Male & 155 & 74.5 \\
\hline & Female & 53 & 25.5 \\
\hline Age in months & $<9$ & 111 & 53.4 \\
\hline & $>=9$ & 97 & 46.6 \\
\hline Place of delivery & Hospital & 199 & 95.7 \\
\hline & Home & 9 & 4.3 \\
\hline
\end{tabular}

Table II: Characteristics of children $(n=208)$ 
Parajuli et al.: Knowledge and Practice Regarding Breastfeeding Among Mothers Attending Immunization Clinic in Nepalgunj Medical College Teaching Hospital

\begin{tabular}{|c|c|c|}
\hline \multirow{2}{*}{$\begin{array}{l}\text { Statement } \\
\text { Benefits to babies }\end{array}$} & \multicolumn{2}{|c|}{ Correct answer } \\
\hline & $\mathrm{n}$ & $\%$ \\
\hline 1.Breastfeeding reduces the risk of respiratory infection & 102 & 49.04 \\
\hline 2. Breastfeeding increases the baby's intelligence & 88 & 42.31 \\
\hline 3. Breastfeeding helps to reduce the incidence of child abuse and neglect & 95 & 45.67 \\
\hline 4. Baby who received breastfeeding is less prone to get diarrhea & 140 & 67.31 \\
\hline 5. Breast milk provides baby with more protection from allergy compared to formula milk & 80 & 38.46 \\
\hline 6. Breastfeeding causes good development of baby's teeth and gum & 100 & 48.08 \\
\hline \multicolumn{3}{|l|}{ Benefits to mothers } \\
\hline 1. Exclusive breastfeeding is beneficial in spacing birth & 55 & 26.44 \\
\hline 2. Breastfeeding helps to stimulate uterine contraction & 70 & 33.65 \\
\hline 3. Mothers who practiced breastfeeding may achieve pre-pregnancy weight faster & 120 & 57.69 \\
\hline 4. Frequent breastfeeding may prevent breast engorgement & 150 & 72.12 \\
\hline 5. Mother who practiced breastfeeding has a low risk of getting breast cancer & 181 & 87.02 \\
\hline 6. Breastfeeding may protect against osteoporosis & 77 & 37.02 \\
\hline \multicolumn{3}{|l|}{ Colostrum } \\
\hline 1. Colostrum is the mother's early milk, which is thick, sticky, and yellowish in colour & 150 & 72.12 \\
\hline 2. Colostrum is difficult to digest and needs to be discarded & 80 & 38.46 \\
\hline 3. Colostrum causes constipation among babies & 73 & 35.10 \\
\hline 4. Colostrum is not able to protect babies from jaundice & 80 & 38.46 \\
\hline \multicolumn{3}{|l|}{ Effective feeding } \\
\hline 1.Baby will gain weight if they receive effective feeding & 122 & 58.65 \\
\hline 2. Correct positioning helps to achieve effective feeding & 112 & 53.85 \\
\hline 3. Babies sleep well after they receive adequate breastfeeding & 190 & 91.35 \\
\hline \multicolumn{3}{|l|}{ Duration of feeding } \\
\hline 1.Breastfeeding should be initiated within 30 minutes after deliver & 155 & 74.52 \\
\hline 2. Breastfeeding should be on demand & 160 & 76.92 \\
\hline 3. Baby should be allowed to breastfeed for at least $10-20$ minutes for each feeding & 79 & 37.98 \\
\hline $\begin{array}{l}\text { 4. Breastfeeding should be continued upto } 2 \text { years even though the baby has received } \\
\text { complementary food }\end{array}$ & 180 & 86.54 \\
\hline Complementary feeding & & 0.00 \\
\hline 1. Complementary feeding should be introduced at 6 months of age & 180 & 86.54 \\
\hline $\begin{array}{l}\text { 2. Mothers may mix breastfeeding and formula feeding once baby starts taking complementary } \\
\text { food }\end{array}$ & 190 & 91.35 \\
\hline \multicolumn{3}{|l|}{ Problems } \\
\hline 1. Breast milk production is influenced by breast size & 112 & 53.85 \\
\hline 2. Mothers will inverted nipples cannot breastfeed their babies & 130 & 62.50 \\
\hline 3. Breastfeeding must be discontinued if mother has cracked nipple & 101 & 48.56 \\
\hline 4. Breastfeeding must be discontinued if baby has jaundice & 110 & 52.88 \\
\hline 5. Breastfeeding must be discontinued if mother has breast engorgement & 80 & 38.46 \\
\hline 6. Breast engorgement may be reduced with cold packs & 120 & 57.69 \\
\hline Practical aspects & 0.00 & \\
\hline 1. Exclusive breastfeeding must be practices until infant is 6 months old & 190 & 91.35 \\
\hline 2. Massage may reduce breast engorgement & 100 & 48.08 \\
\hline 3. Giving water to baby is encouraged after every breastfeeding & 120 & 57.69 \\
\hline 4. Belching after feeding shows that the baby is full & 190 & 91.35 \\
\hline 5.Babies who get enough feeding will pass urine more frequently & 112 & 53.85 \\
\hline 6. Oral thrush frequently happens to babies who breastfeed & 95 & 45.67 \\
\hline
\end{tabular}

Table III: Knowledge regarding breastfeeding among participants ( $n=208)$ 
In addition, table III shows that knowledge of mothers regarding effective breastfeeding is excellent (91\%) regarding babies sleeps well after receiving adequate breastfeeding. Their knowledge is sufficient regarding duration of breastfeeding (ranging from $74.5 \%$ to $84.5 \%$ ) except for the fact that baby should be allowed to breastfeed for at least 10-20 minutes for each feeding. Their knowledge regarding complementary feeding was sufficient as $91.4 \%$ regognized that they may mix breastfeeding and formula feeding once baby starts taking complementary food while $86.5 \%$ were aware that complementary feeding should be introduced at 6 months of age.

It is evident from table 3 that the mothers' knowledge regarding problems with breastfeeding is insufficient. For example, only $39 \%$ answered that breastfeeding must be continued if mother has breast engorgement, $48.5 \%$ answered that breastfeeding must be continued if the mother has cracked nipple and $53.9 \%$ answered that breast milk production is not influenced by breast size.

As shown in table 3, the knowledge of mothers regarding practical aspects of breastfeeding is sufficient in some of them as exclusive breastfeeding must be practiced until the infant was 6 months old and blenching after feeding showed baby was full (91\%), while it was insufficient in other aspects as false beliefs like giving water to baby is encouraged after every breastfeeding (54\%), oral thrush was frequent in babies who breastfeed was (46\%), massage may reduce breast engorgement (48\%).

Figure 1 demonstrates that overall mother's breastfeeding knowledge was good among $35 \%$ and excellent among $22 \%$ of them while it was unsatisfactory among $43 \%$ of the mothers.

\section{Practices regarding breastfeeding}

Breastfeeding in the first 6 months was practiced by $42 \%$ of the participated mothers. Only $23 \%$ practiced exclusive breast feeding. Among those who breastfed their babies, 51\% initiated breastfeeding in the first hour of birth, $21 \%$ between 2-4 hours and only $20 \%$ initiated it after 24 hours. Only $73 \%$ of mother had not given any prelacteal feeding to their babies.

\section{Barriers to Exclusive Breast Feeding}

As obvious from figure 4, no enough breast milk (47.9\%), crying hungry (31.5\%), work-related problems (13.7\%), mother illness (6.8\%) were the commonly reported barriers against exclusive breastfeeding.

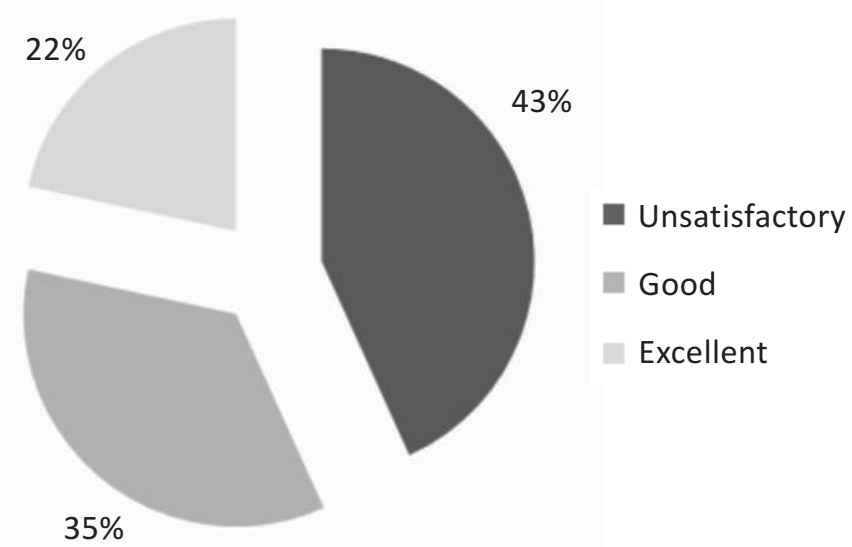

Figure 1: Level of knowledge regarding breastfeeding

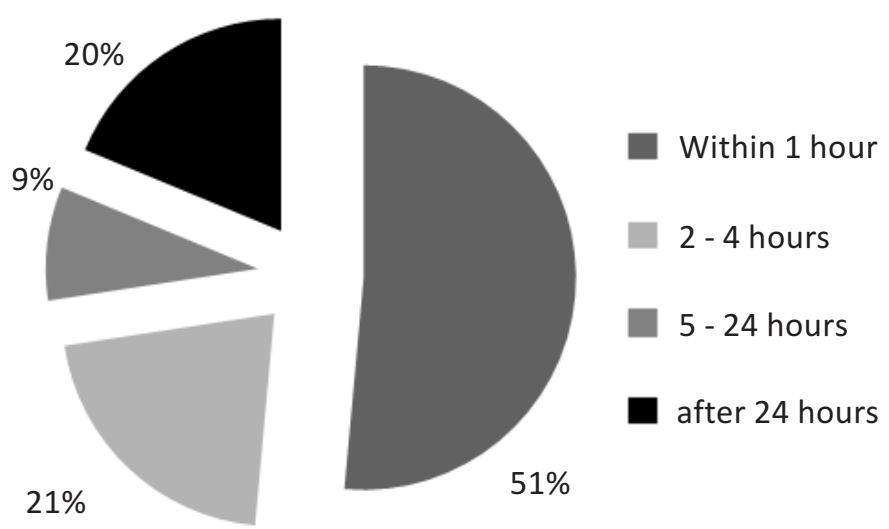

Figure 2: Initiation of breast milk

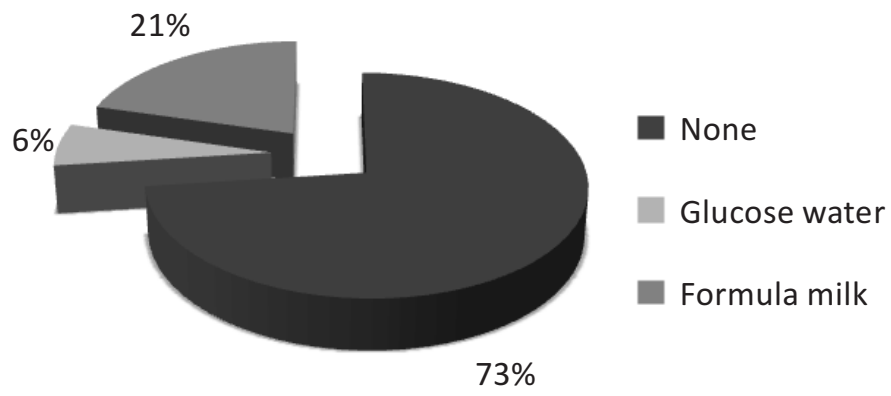

Figure 3: Use of prelacteal feeding 


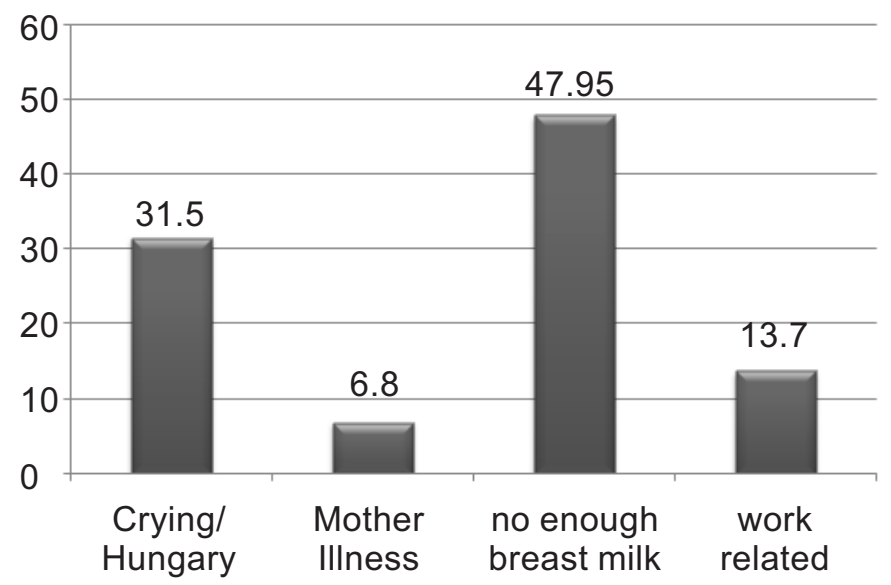

Figure 4: Barriers against exclusive breastfeeding

\section{DISCUSSION}

Exclusive breastfeeding for the first 6 months of life improves the growth, health and survival status of newborns ${ }^{21}$ and is one of the most natural and best forms of preventive medicine ${ }^{22}$. Exclusive breastfeeding plays a pivotal role in determining the optimal health and development of infants, and is associated with a decreased risk for many early-life diseases and conditions, including otitis media, respiratory tract infection, diarrhea and early childhood obesity ${ }^{23}$.

Currently the recommendations from the global strategy for infant and young child feeding, developed by the World Health Organization and UNICEF, is that infants should be exclusively breastfed for the first 6 months of life ${ }^{22}$. Still, less than $40 \%$ of infants under 6 months of age in the developing world are exclusively breastfed ${ }^{24}$.

Despite UNICEF and WHO recommendations, only $53 \%$ of children under 6 months of age were exclusively breastfed in Nepal. Median duration of any breastfeeding is about 34 months and exclusive breastfeeding were about 4.2 months ${ }^{25}$. Thought $91 \%$ had good knowledge regarding EBF, rate of EBF practice up to six months of age in our study (23\%) was substantially lower than the $53 \%$ finding in the National Demographic Health Survey (NDHS) in $2006^{19}$. Poverty and ignorance were the main reasons for this practice, which is one of the major causes of malnutrition among infants ${ }^{25}$. In a study by Chudasma RK et al in Rajkot also showed the prevalence of exclusive breast feeding at 6 months of age of infants was found to be $62 \%(26)$.

Foo LL et al reported prevalence rate of $21 \%$ which is similar compared to present study ${ }^{27}$. Whereas the study done by Yadavannavar MC and Shailaja S Patil showed only $13.36 \%$ of mothers practiced almost exclusive breast feeding up to 4 months $^{28}$. This shows despite the demonstrated benefits of breast feeding, breast feeding prevalence and duration in many countries exclusive breast feeding for the first 6 months of life are still lower than the International recommendations of
$\mathrm{WHO}^{2}$. But it should also be considered that prevalence of EBF will also depend upon the methods of data collection and definitions used in the study.

Preparation of mothers before they give birth is fundamental to the success of exclusive breastfeeding. However in our study it was seen that only $59 \%$ of the women had received any advice on breastfeeding during antenatal period. Similar study done in Pokhara showed only $53 \%$ of the women received advice on breastfeeding during ANC visits ${ }^{29}$. In India advice were received only by $48 \%$ of women ${ }^{30}$. Support and counseling should be available routinely during ante-natal care, to prepare mothers; at the time of birth to help them initiate breastfeeding; and in the postnatal period to ensure that breastfeeding is fully established.

Regarding initiation of breastfeeding $74.5 \%$ of mothers had idea on starting breast feeding within $1 / 2-1 \mathrm{hr}$ of birth (table III) and in practice only $51 \%$ mothers started breast feeding within $1 / 2-1 \mathrm{hr}$ of birth. Data from 2006 NDHS showed that nearly 1 in 3 children were breast-fed within $1 / 2-1 \mathrm{hr}^{19}$. One study done in Dharan showed only $10 \%$ of the mother had knowledge regarding initiation of breastfeeding but $41.5 \%$ practice it ${ }^{31}$. According to a study conducted in rural Ghana, it was concluded that if all women initiated breastfeeding within 1 hour of birth, $22 \%$ of the infants would be saved from death. In the Indian context, this means that 250,000 nenates can be saved from death annually by just one act of initiation of breastfeeding within 1 hour of birth ${ }^{32}$. In one study done in India, it was seen that although $92 \%$ of the mothers knew the recommendation of initiating breastfeeding within one hour only $36 \%$ had actually done $\mathrm{it}^{30}$.

One of the major reasons for the delay in our study was that the child was sick. This could be because of the fact that the study was conducted in a tertiary care institute where mothers whose babies were sick were retained in the hospital for more days and were included in the study. The second reason was that there was delay in shifting from labour room. The other reasons (too tired to sit up and feed, baby was sleeping) only reflected that the mothers were not motivated adequately for initiating breastfeeding within one hour of birth. Hence intensive efforts need to be put for the timely initiation of breastfeeding preferably within the labour room itself if there is delay in shifting and the importance of early initiation of breastfeeding needs to be stressed to the mothers in the antenatal period itself.

The unique nutritional and antibody properties of colostrum and the disadvantages to those infants not fed with colostrum are now well recognized and documented ${ }^{2}$. In our study, only $38 \%$ of the mothers knew that colostrum needs to be given which is very low compared to others studies in India where the importance of colostrum was known to $75-90 \%$ of the mothers $^{33,34}$. 
The mother's perception of "no enough breast milk" is a wellknown problem hindering optimal EBF practice in many communities ${ }^{35,36}$. A key reason, however, why a child could remain hungry is not because breast milk is insufficient but because women do not spend adequate time on breast feeding due to the pressure of house work or are not aware that the milk should be exhausted from one breast before feeding from the second breast ${ }^{37}$. In our study too, "no enough breast milk" was also the main reason for introducing other foods, especially other milk, semi-solid porridge, before six months of age. A total of $73(35 \%)$ infants were introduced to other foods (semi/solid or animal milk) before six months of age. Of which $48 \%$ reported due to insufficient breast milk production. This finding is concordant with another breast feeding study conducted among employed women in periurban areas of Kathmandu ${ }^{38}$, and a quantitative and qualitative study conducted among 750 young children residing in Far Western district of Baitadi, Nepa $\left.\right|^{39}$. It is also noteworthy to mention that in our setting, rice is introduced at 5 - 6 months of age with a special ceremony called Pasni, or the rice feeding ceremony, which also seems to interfere with EBF for up to six months of age $^{40}$.

In the present study, several limitations should be considered which depend upon the methods of data collection. Measuring EBF prevalence using recall since birth is difficult and may be inaccurate. This required a long recall period and some women might have forgotten the time when liquids including water or semi-solids were introduced and given wrong accounts, which could be overcome only by a prospective design followed from birth. Moreover this study included only mothers attending for vaccination clinic in tertiary hospital, and the results may not be representative of the whole nation.

\section{CONCLUSIONS}

The prevalence of EBF for up to 6 months of age was still low as per WHO recommendations. The mother's perception of "insufficient breast milk" was also the main reason for introducing other foods. Most of the mothers did not receive any information on breast feeding and even hospital delivered babies had a low rate of EBF. So it is advisable to carry out for EBF promotion a strategy by making a guideline for breast feeding education focusing that mother's milk - a life milk' within the existing health care system such as the antenatal, after delivery and vaccination clinics.

\section{REFERENCES}

1. Azubuike N, Nkanginieme KE. 2nd ed. Port Harcourt (Nig): University of Port Harcourt Press; 2007. Infant feeding. Paediatrics and Child Health in a Tropical Region;224-67.

2. WHO.WHO/UNICEF. Global Strategy for Infant and Young Child Feeding; 2003. Available from;

http://apps.who.int/iris/bitstream/10665/42590/1/924156221 8.pdf?ua $=1 \& u a=1$

3. Gupta A, Arora V. The State of World's Breastfeeding -Tracking Implementation of the Global Strategy for Infant and Young Child Feeding. International Baby Food Action Network (IBFAN), Asia
Pacific. South Asia report. Feb 2007.

4. Black RE, Victora CG, Walker SP, and the Maternal and Child Nutrition Study Group. Maternal and child undernutrition and overweight in low-income and middle-income countries. Lancet 2013; published online.

5. Subbiah N. A Study to assess the Knowledge, Attitude, Practice and Problems of Postnatal Mothers regarding Breastfeeding. Nursing J Ind 2003; 94 (8) : 177-179

6. World Health Organization. Infant and young child feeding Model Chapter for textbooks for medical stu-dents and allied health professionals. World Health Organization. 2009.

7. WHO Collaborative Study Team on the Role of Breast-feeding on the Prevention of Infant Mortality. Effect of breastfeeding on infant and childhood mortality due to infectious diseases in less developed countries: a pooled analysis. Lancet 2000; 355:451-455.

8. Bahl R, Frost C, Kirkwood BR, Karen E, Martines J, Bhandari $\mathrm{N}$ et al. Infant feeding patterns and risks of death and hospitalization in the first half of infancy: multicentre cohort study. World Health Organization, 2005; 83: 418-426

9. Dadhich JP, Gupta A. Assessment of Status of Infant and Young Child Feeding (IYCF) practice, policy and program-Achievements and Gaps. Breast feeding promotion network of India, 2005.

10. Bhutta ZA, Ahmed T, Black RE, Cousens S, Dewey K, Giugliani E, et al. What works? Interventions for maternal and child under nutrition and survival. Lancet 2008;371:417-40.

11. Darmstadt GL, Bhutta ZA, Cousens S, Adam T, Walker N de BL. Evidence-based, cost-effective interventions: how many newborn babies can we save? Lancet 2005;365:977-88.

12. Edmond KM, Zandoh C., Quigley MA., Amenga-Etego S., OwusuAgyei S, Kirkwood BR. Delayed breastfeeding initiation increases risk of neonatal mortality. Pediatrics 2006;117: e3806.

13. Cantrill RM, Creedy DK, Cooke M. An Australian study of midwives' breast-feeding knowledge. Midwifery 2003;19:31017.

14. Forster DA., McLachlan HL, Lumley J. Factors associated with breastfeeding at six months postpartum in a group of Australian women. International Breastfeeding Journal 2006; 1:18.

15. Sable MR, Patton CB. Prenatal Lactation Advice and Intention to Breastfeed: Selected Maternal Characteristics. J Hum Lact 1998;14(1):35-40.

16. Hila JS. Nurses' attitudes, knowledge, and beliefs related to the promotion of breastfeeding among women who bear children during adolescence. J Pediatr Nursing 2004; 19(3):176-83.

17. Humenick SS, Hill P, Spiegelberg P. Breastfeeding and Health Professional Encouragement. J Hum Lact 1998;14(4):305-10.

18. Richard S, O'Connor K, Ruth L. Pediatricians Practices and Attitudes Regarding Breastfeeding Promotion, Pediatrics 1999;103(3):1.

19. Ministry of Health and Population (MOHP), Nepal, NEW ERA and Macro International Inc: Nepal Demographic Health Survey 2006 Kathmandu, Nepal: Ministry of Health and population, New ERA, and Macro International Inc;2007.

20. Alina T, Ismail T, Sulaiman Z. Reliability and validity of a Malayversion questionnaire assessing knowledge of breastfeeding. Malaysian J Med Sci 2010;17(3):32-39.

21. World Health Organization: Indicators for assessing infant and young child feeding practices. Washington DC, USA: WHO; 2008.

22. World Health Organization: The Global Strategy for Infant and Young Child Feeding. Geneva: WHO; 2003.

23. Agho KE, Dibley MJ, ODiase J, Ogbonmwan SM. Determinants of 
exclusive breastfeeding in Nigeria. BMC Pregnancy Childbirth 2011;11:2.

24. UNICEF: Maternal and Newborn Health. The State of the sowc08/docs/sowc08.pdf (accessed September 2010).

25. Khan ME. Breast - feeding and Weaning Practices in India. Asia Pac Popul J 1990;5(1):71-88.

26. Chudasama RK, Amin CD, Parikh YN. Prevalence of exclusive breast feeding and its determinants in first 6 months of life: $A$ prospective study. Online J Health Allied Scs. 2009;8(1):3.

27. Foo LL, Quek SJS, Ng SA et al. Breast feeding prevalenceand practice among Singaporean, Chinese, Malay and Indian Mothers. Health Promotion International. 2005;20:229-37.

28. Yadavannavar MC, Patil SS. Socio-cultural factors affecting breast feeding practices and decisions in rural women. International Journal of Plant, Animal and Environmental Sciences. June - Aug 2011;1(2):2231-4490.

29. Mainali P, Sayami S, Shrestha B, Subedi N. Breast Feeding Patterns and Factors Influencing Exclusive Breast Feeding Practice. Journal of Gandaki Medical College Nepal. 2014;7(2):9-14.

30. Maheswari Ekambaram, Vishnu Bhat B, Mohamed Asif Padiyath Ahamed. Knowledge, attitude and practice regarding breastfeeding among postnatal mothers, Jawaharlal Institute of Postgraduate Medical Education and Research, Puducherry, India. 2010;14(2):119-22.

31. RN Chaudhary, T Shah, S Raja. Knowledge and practice of mothers regarding breastfeeding: A hospital based study. Knowledge \& practice in breast feeding. September-December 2011;9(3):194-200.

32. Gupta A, Arora V, Bhatt B. The State of World's Breastfeeding: India Report card 2006. International Baby Food Action Network (IBFAN), Asia Pacific. India. 2006.

33. Subbiah N. A Study to assess the Knowledge, Attitude, Practice and Problems of Postnatal Mothers regarding Breastfeeding. Nursing J Ind 2003;94 (8):177-79.

34. Tiwari $\mathrm{V}$, Singh $\mathrm{A}$. Knowledge, attitude and practice regarding breastfeeding in an urban area of Fazidabad district (U.P). Indian J Prev Soc Med 2007;38(1):18-22.

35. WHO: Indicators for assessing infant and young child feeding practices: Conclusions of a consensus meeting held 6 - 8 November 2007 in Washington D.C., USA. 2007.

36. Fjeld E, Siziya S, Katepa-Bwalya M, Kankasa C, Moland KM, Tylleskar T. 'No sister, the breast alone is not enough for my baby'. A qualitative assessment of potentials and barriers in the promotion of exclusive breast feeding in Southern Zambia. Int Breastfeed J. 2008;3(1):26.

37. Kumudha, khan ME, Avishek Hazar. Increasing early and exclusive breast feeding in rural Uttar. Journal of Family Welfare. Special Issue. 2010;56.

38. Moffat T. Breast feeding, wage labor, and insufficient milk in periurban Kathmandu, Nepal. Med Anthropol. 2002;21(2):207-30.

39. HKI: Breast feeding and complementary feeding practices are less than adequate among mothers of children 12 - 23 months in the Baitadi district of Nepal. Nepal Nutrition and Food Security Bulletin. Helen Keller International (HKI). 2010.

40. Ulak et al. Infant feeding practices in Bhaktapur, Nepal: a crosssectional, health facility based survey. International Breastfeeding Journal. 2012;7:1. 